\title{
Seroepidemiology of pandemic influenza A (H1N1) 2009 virus infections in Pune, India
}

\author{
Babasaheb V Tandale, Shailesh D Pawar, Yogesh K Gurav, Mandeep S Chadha, Santosh S Koratkar, Vijay N Shelke, \\ Akhilesh C Mishra*
}

\begin{abstract}
Background: In India, Pune was one of the badly affected cities during the influenza A (H1N1) 2009 pandemic. We undertook serosurveys among the risk groups and general population to determine the extent of pandemic influenza A (H1N1) 2009 virus infections.

Methods: Pre-pandemic sera from the archives, collected during January 2005 to March 2009, were assayed for the determination of baseline seropositivity. Serosurveys were undertaken among the risk groups such as hospital staff, general practitioners, school children and staff and general population between $15^{\text {th }}$ August and $11^{\text {th }}$ December 2009. In addition, the PCR-confirmed pandemic influenza A (H1N1) 2009 cases and their household contacts were also investigated. Haemagglutination-inhibition ( $\mathrm{HI})$ assays were performed using turkey red blood cells employing standard protocols. A titre of $\geq 1: 40$ was considered seropositive.
\end{abstract}

Results: Only $2(0.9 \%)$ of the 222 pre-pandemic sera were positive. The test-retest reliability of HI assay in 101 sera was $98 \%$ for pandemic H1N1, 93.1\% for seasonal H1N1 and 94\% for seasonal H3N2. The sera from 48 (73.8\%) of 65 PCR-confirmed pandemic H1N1 cases in 2009 were positive. Seropositivity among general practitioners increased from $4.9 \%$ in August to $9.4 \%$ in November and $15.1 \%$ in December. Among hospital staff, seropositivity increased from $2.8 \%$ in August to $12 \%$ in November. Seropositivity among the schools increased from $2 \%$ in August to $10.7 \%$ in September. The seropositivity among students (25\%) was higher than the school staff in September. In a general population survey in October 2009, seropositivity was higher in children (9.1\%) than adults (4.3\%). The 15-19 years age group showed the highest seropositivity of 20.3\%. Seropositivity of seasonal H3N2 (55.3\%) and H1N1 (26.4\%) was higher than pandemic H1N1 (5.7\%) ( $n=2328)$. In households of 74 PCR-confirmed pandemic H1N1 cases, 25.6\% contacts were seropositive. Almost 90\% pandemic H1N1 infections were asymptomatic or mild. Considering a titre cut off of 1:10, seropositivity was 1.5-3 times as compared to 1:40.

Conclusions: Pandemic influenza A (H1N1) 2009 virus infection was widespread in all sections of community. However, infection was significantly higher in school children and general practitioners. Hospital staff had the lowest infections suggesting the efficacy of infection-control measures.

\section{Background}

The first pandemic influenza A (H1N1) 2009 case in India was reported in Hyderabad city on $16^{\text {th }}$ May 2009 [1]. Pune city reported the first pandemic influenza A (H1N1) 2009 case on $22^{\text {nd }}$ June 2009. The first pandemic death in Pune on $3^{\text {rd }}$ August 2009 caused panic in the general public. Subsequently, widespread transmission was reported in community [2].

\footnotetext{
* Correspondence: acm1750@rediffmail.com

National Institute of Virology, 20-A, Dr. Ambedkar Road, Pune 411001, India
}

The critical need of population-based serology has been advocated to determine the extent of infection and age-specific infection rates [3]. Wide geographical variations are expected in the incidence of infection in different populations. Therefore, large serosurveys covering different areas and age groups at different times are necessary to understand the extent of the infection in community. Further, seropositivity in population may provide appropriate denominator for pandemic severity estimates and the data for delineation of risk populations for priority in vaccination [4].
C Biomed Central

C 2010 Tandale et al; licensee BioMed Central Ltd. This is an Open Access article distributed under the terms of the Creative Commons Attribution License (http://creativecommons.org/licenses/by/2.0), which permits unrestricted use, distribution, and reproduction in any medium, provided the original work is properly cited. 
Several studies have been conducted to address the issues of cross-reactivity or pre-existing immunity using sera from the archives or collections from the routine diagnostic or screening programmes [5-10]. Some studies were done involving hospital staff [11], blood donors and patients without acute respiratory illness [12].

Pune is one of the cities in India reporting higher number of cases and deaths during this pandemic [2]. We report results of serosurveys undertaken in Pune in the risk groups, general population and household contacts of the PCR-confirmed cases. We also tried to detect the change in seroprevalence over time by resurveys in the selected risk groups.

\section{Methods}

\section{Study area}

Pune is the second largest urban agglomeration in Maharashtra state in India. Its population is about 3.76 million as per the 2001 Census. Pune has tropical climate with an average annual rainfall of $580.9 \mathrm{~mm}$. Usually, June to September are the monsoon months. Incidence of seasonal influenza is higher in rainy and winter seasons though activity continues throughout the year. Seasonal influenza A (H3N2) was the most predominant strain in the year 2009 [2].

\section{Study design and sampling}

For determining baseline seropositivity, anonymous leftover sera from the archives, referred for dengue diagnosis during January 2005- March 2009 were selected randomly and tested. PCR-confirmed pandemic influenza A (H1N1) 2009 cases were also sampled for serodiagnosis along with their household members for understanding the transmission. The study subjects volunteered and provided informed consents before depositing blood samples. An effort was made to broadly represent major divisions of Pune city for selecting the risk groups and the community clusters for the survey.

The present cross-sectional serological survey was undertaken between August 15 and December 11, 2009. Hospital staff, general practitioners and school children and staff were surveyed as the risk groups. Hospital staff from nine hospitals included doctors, nurses and other support staff who were actually involved in patient care activities like screening, sampling, diagnosis, isolation and critical care in the hospitals designated for pandemic flu patients. General practitioners were the medical practitioners from nine different areas of the city and worked mostly as family physicians in community and the first point of contact for pandemic flu patients. Hospital staff was resurveyed after nine weeks and general practitioners were resurveyed after 13 weeks. School staff from five schools was surveyed on 15th August
2009. In September, children and the staff of four schools were surveyed. We considered school children and staff as the risk groups due to the possibility of higher transmission in the schools. Children from the schools were selected from all the divisions reporting cases along with at least one unaffected division or class.

Office staff, railway commuters, slum-dwellers and general population were surveyed in September. Railway commuters travelling daily by the same local train were surveyed for studying the effect of crowding. Office staff was surveyed to understand the extent of infection in workplaces as an indirect measure of the population. In a general population survey in October 2009, cluster sampling was employed for selecting 20 localities spread over wide areas with the inclusion of slums proportionate to the size. In each selected locality, a house-tohouse survey was done and all the family members were invited to participate in the study.

Informed consents were obtained from the adult volunteer participants and from the parents of children in schools and population. Administrative approvals were obtained from the health, municipal and school authorities and religious leaders. The study was reviewed and approved by the institutional ethical committee for research on human subjects at the National Institute of Virology, Pune, India and was considered exempt as the study was undertaken during the ongoing outbreak and was essential for guiding mitigation activities.

\section{Case definitions}

Influenza-like illness was defined as the patient presenting with fever and either of sore throat or cough or both or a recent history of such symptoms [13]. A PCRconfirmed case of pandemic influenza A (H1N1) 2009 was defined as an influenza-like illness patient positive for viral RNA by reverse transcriptase polymerase chain reaction (RT-PCR).

\section{Data and specimen collection}

Information about the subject's age, gender, area of residence, occupation, workplace, number of persons in the household, travel, exposure details, and symptoms of respiratory illness, duration of disease, medical consultation, treatment, hospitalisation and outcome was recorded. Blood samples (3-5 ml) were collected in evacuated tubes by venipuncture, kept at room temperatures for 30-45 minutes for allowing clot retraction and transported on wet ice within 4-6 hours of sampling. Sera were separated by centrifugation. Aliquots were made and stored at $-20^{\circ} \mathrm{C}$ until testing.

\section{Laboratory procedures}

All sera were treated with receptor destroying enzyme (Denka Seiken, Japan) for removal of non-specific 
inhibitors. In each assay, serum control included testing of serum without test antigen. Sera without non-specific agglutinins showed button formation, whereas sera with non-specific agglutinins showed haemagglutination. Sera with non-specific agglutinins were treated with turkey red blood cells, which removed non-specific agglutinins. The final dilution of the serum was 1:10. The pandemic influenza A (H1N1) 2009 virus was grown in 10-day-old specific-pathogen-free embryonated chicken eggs (Venky's India Limited, Pune), inactivated using beta-propiolactone and used as an antigen. The seasonal influenza A (H1N1) and A (H3N2) antigens were obtained from World Health Organization Collaborating Center for influenza (Centers for Disease Control and Prevention, Atlanta, USA) and were used in the assays. Haemagglutination-inhibition (HI) assay is routinely used for determination of the antibodies in sera [14]. HI assay was performed for detection of antibodies using $0.5 \%$ turkey red blood cells. Titres were reported as the reciprocal of the highest dilution showing complete inhibition. Twofold dilutions of sera were made starting with 1:10 and the highest dilution of 1:1280. An HI antibody titre of 1:40 or more was considered seropositive as reported in most studies during the ongoing pandemic. HI assay was repeated for test-retest reliability. We also estimated the proportion of sera with antibody titre at or above the minimum detection limit of 1:10 against pandemic H1N1 virus.

\section{Statistical methods}

Sample sizes were estimated considering the absolute precision of $5 \%$ at $95 \%$ confidence level. Seropositivity was reported as percentages with $95 \%$ confidence intervals. Age groups were categorized as 0-4, 5-9, 10-14, $15-19,20-29,30-39,40-49,50-59$ and $\geq 60$ years. An age $\geq 60$ years was further divided as $60-69$ and $\geq 70$ years. We analyzed seropositivity in broad age groups like children (0-19 years), adults (20-59 years) and elderly ( $\geq 60$ years). The age-specific seropositivity was calculated and adjusted to the population of Pune (2001 Census) by direct age-standardization method [15].

\section{Results}

Age and sex distribution of the study subjects sampled during the pre-pandemic period and those sampled from different study groups at various time points during the pandemic period is presented in Table 1. Prepandemic sera $(\mathrm{n}=222)$ were collected between January 2005 and March 2009. Among them, 64 (28.8\%) were $<20$ years, $69(31.1 \%)$ were aged $20-59$ years and 85 $(38.3 \%)$ were aged $\geq 60$ years. HI antibody titre $\geq 1: 40$ was detected in sera of only $2(0.9 \%)$ subjects, both aged $\geq 60$ years. Considering the minimum detectable titre of $1: 10,6(2.7 \%)$ sera were positive, of which 4 were aged $\geq 60$ years and 2 were aged 40-59 years (data not shown).

Sera from 48 (73.8\%) of 65 PCR-confirmed pandemic influenza A (H1N1) 2009 cases were positive (Table 2). We treated 441 sera with turkey red blood cells. These sera were randomly distributed and were few as compared to the large number of sera processed in the study. The test-retest reliability of HI assay in 101 sera was $98 \%$ for pandemic $\mathrm{H} 1 \mathrm{~N} 1,93.1 \%$ for seasonal H1N1 and $94 \%$ for H3N2. The seropositivity (titre $\geq 1: 40$ ) in different study groups at various time points during the pandemic (Table 2) is described in the following sections.

\section{Seropositivity in risk groups \\ A. Hospital staff}

In the last week of August, 2.8\% of the 495 hospital staff was seropositive. Seropositivity was not significantly different among doctors $(7,2.9 \%)$, nurses $(3,3 \%)$ and other staff $(4,2.7 \%)$ (data not shown). In the last week of October, seropositivity was $4.8 \%$ and it was not significantly different from that in August. In November, seropositivity $(12 \%)$ was significantly $(\mathrm{p}<0.001)$ higher than at the first survey (Table 2). In all serum sets, seropositivity in the 20-39 years age group was not significantly different than in the 40-59 years age group (data not shown). Among 104 subjects found seronegative at the first survey in August, 6 (5.8\%) became seropositive at resampling after 9 weeks indicating new infections during the period.

\section{B. General practitioners}

In the last week of August, $4.9 \%$ of the 385 general practitioners were seropositive. The seropositivity in November (9.4\%) and in December (15.1\%) (Table 2) was significantly $(\mathrm{p}<0.001)$ higher than in August. Seropositivity in the $20-39$ years age group $(17 / 132,12.9 \%)$ was significantly $(\mathrm{p}<0.05)$ higher than in the $40-59$ years age group $(5 / 123,4.1 \%)$ in the subjects sampled only in November (data not shown). Among 43 subjects found seronegative at the first survey in August, 5 (11.6\%) became seropositive at resampling after 13 weeks indicating new infections during the period.

\section{School children and staff}

Seropositivity among school staff was $2 \%$ on $15^{\text {th }}$ August 2009 and it increased to $10.7 \%$ by the end of September (Table 2). In the schools with the reports of PCR-confirmed cases, $11.8 \%$ school staff was seropositive as compared to $4.2 \%$ in a school without PCR-confirmed case. Among 96 subjects found seronegative at the first survey in August, 4 (4.2\%) became seropositive at resampling after 5 weeks indicating new infections during the period.

Influenza-like illness was not reported by any of these 4 seropositive subjects. 
Table 1 Age and sex distribution of subjects in different study groups at various time points

\begin{tabular}{|c|c|c|c|c|c|}
\hline Study groups & Period of sampling & Age group & $\begin{array}{l}\text { Total, } \\
\text { n (\%) }\end{array}$ & $\begin{array}{c}\text { Males, } \\
\text { n (\%) }\end{array}$ & $\begin{array}{c}\text { Females, } \\
\mathrm{n}(\%)\end{array}$ \\
\hline \multirow[t]{6}{*}{ Pre-pandemic } & January 2005 - March 2009 & All & $222^{*}$ & 115 & 102 \\
\hline & & $<20$ & $64(28.8)$ & $45(39.1)$ & $18(17.6)$ \\
\hline & & $20-39$ & $22(9.9)$ & $16(13.9)$ & $6(5.9)$ \\
\hline & & $40-59$ & $47(21.2)$ & $23(20.0)$ & $24(23.5)$ \\
\hline & & $\geq 60$ & $85(38.3)$ & $31(27.0)$ & $54(52.9)$ \\
\hline & & NA & $4(1.8)$ & $0(0.0)$ & $0(0.0)$ \\
\hline \multirow[t]{12}{*}{ Hospital staff } & August 2009 & All & 495 & 276 & 219 \\
\hline & & $20-39$ & $317(64.0)$ & $186(67.4)$ & $131(59.8)$ \\
\hline & & $40-59$ & $173(34.9)$ & $88(31.9)$ & $85(38.8)$ \\
\hline & & NA & $5(1.0)$ & $2(0.7)$ & $3(1.4)$ \\
\hline & October 2009 & All & 524 & 250 & 274 \\
\hline & & $20-39$ & $295(56.3)$ & $154(61.6)$ & $141(51.5)$ \\
\hline & & $40-59$ & $225(42.9)$ & $94(37.6)$ & $131(47.8)$ \\
\hline & & NA & $4(0.8)$ & $2(0.8)$ & $2(0.7)$ \\
\hline & November 2009 & All & 385 & 183 & 202 \\
\hline & & $20-39$ & $294(76.4)$ & 159 (86.9) & $135(66.8)$ \\
\hline & & $40-59$ & $86(22.3)$ & $23(12.6)$ & $63(31.2)$ \\
\hline & & NA & $5(1.3)$ & $1(0.5)$ & $4(2.0)$ \\
\hline \multirow[t]{14}{*}{ General practitioners } & August 2009 & All & 385 & 244 & 141 \\
\hline & & $20-39$ & $148(38.4)$ & 85 (34.8) & $63(44.7)$ \\
\hline & & $40-59$ & $200(51.9)$ & $131(53.7)$ & $69(48.9)$ \\
\hline & & $\geq 60$ & $33(8.6)$ & $26(10.7)$ & $7(5.0)$ \\
\hline & & NA & $4(1.0)$ & $2(0.8)$ & $2(1.4)$ \\
\hline & November 2009 & All & 278 & 213 & 65 \\
\hline & & $20-39$ & $132(47.5)$ & $98(46.0)$ & $34(52.3)$ \\
\hline & & $40-59$ & $123(44.2)$ & $98(46.0)$ & $25(38.5)$ \\
\hline & & $\geq 60$ & $21(7.6)$ & $15(7.0)$ & $6(9.2)$ \\
\hline & & NA & $2(0.7)$ & $2(0.9)$ & $0(0.0)$ \\
\hline & December 2009 & All & 225 & 156 & 69 \\
\hline & & $20-39$ & $167(74.2)$ & $111(71.2)$ & $56(81.2)$ \\
\hline & & $40-59$ & $52(23.1)$ & $39(25.0)$ & $13(18.8)$ \\
\hline & & $\geq 60$ & $6(2.7)$ & $6(3.8)$ & $0(0.0)$ \\
\hline \multirow[t]{10}{*}{ School staff } & August 2009 & All & 348 & 97 & 251 \\
\hline & & $20-39$ & $152(43.7)$ & $34(35.1)$ & $118(47.0)$ \\
\hline & & $40-59$ & $178(51.1)$ & $54(55.7)$ & $124(49.4)$ \\
\hline & & $\geq 60$ & $6(1.7)$ & $4(4.1)$ & $2(0.8)$ \\
\hline & & NA & $12(3.4)$ & $5(5.2)$ & $7(2.8)$ \\
\hline & September 2009 & All & 177 & 27 & 150 \\
\hline & & $20-39$ & $100(56.5)$ & $17(63.0)$ & $83(55.3)$ \\
\hline & & $40-59$ & 67 (37.9) & $7(25.9)$ & $60(40.0)$ \\
\hline & & $\geq 60$ & $5(2.8)$ & $0(0.0)$ & $5(3.3)$ \\
\hline & & NA & $5(2.8)$ & $3(11.1)$ & $2(1.3)$ \\
\hline School children & September 2009 & $\begin{array}{c}\text { All } \\
(<20)\end{array}$ & 2527 & 755 & 1772 \\
\hline \multirow[t]{5}{*}{ Railway commuters } & September 2009 & All & 225 & 150 & 75 \\
\hline & & $20-39$ & $40(17.8)$ & $22(14.7)$ & $18(24.0)$ \\
\hline & & $40-59$ & 49 (21.8) & $37(24.7)$ & $12(16.0)$ \\
\hline & & $\geq 60$ & $1(0.4)$ & $1(0.7)$ & $0(0.0)$ \\
\hline & & NA & $135(60.0)$ & $90(60.0)$ & $45(60.0)$ \\
\hline \multirow[t]{2}{*}{ Office staff } & September 2009 & All & 233 & 175 & 58 \\
\hline & & $20-39$ & $152(65.2)$ & $104(59.4)$ & $48(82.8)$ \\
\hline
\end{tabular}


Table 1 Age and sex distribution of subjects in different study groups at various time points (Continued)

\begin{tabular}{|c|c|c|c|c|c|}
\hline & & $40-59$ & $78(33.5)$ & $69(39.4)$ & $9(15.5)$ \\
\hline & & NA & $3(1.3)$ & $2(1.1)$ & $1(1.7)$ \\
\hline \multirow[t]{6}{*}{ Slum-dwellers } & September 2009 & All & 651 & 292 & 359 \\
\hline & & $<20$ & $252(38.7)$ & $139(47.6)$ & $113(31.5)$ \\
\hline & & $20-39$ & $248(38.1)$ & $95(32.5)$ & $153(42.6)$ \\
\hline & & $40-59$ & $96(14.7)$ & $33(11.3)$ & $63(17.5)$ \\
\hline & & $\geq 60$ & $27(4.1)$ & $13(4.5)$ & $14(3.9)$ \\
\hline & & NA & $28(4.3)$ & $12(4.1)$ & $16(4.5)$ \\
\hline \multirow[t]{6}{*}{ General population } & $\begin{array}{c}\text { October } \\
2009\end{array}$ & All & 2520 & 1138 & 1382 \\
\hline & & $<20$ & $877(34.8)$ & $471(41.4)$ & $406(29.4)$ \\
\hline & & $20-39$ & $885(35.1)$ & $335(29.4)$ & $550(39.8)$ \\
\hline & & $40-59$ & $515(20.4)$ & $213(18.7)$ & $302(21.9)$ \\
\hline & & $\geq 60$ & $226(9.0)$ & $107(9.4)$ & $119(8.6)$ \\
\hline & & NA & $17(0.7)$ & $12(1.1)$ & $5(0.4)$ \\
\hline \multirow[t]{5}{*}{ PCR-confirmed cases } & September - October 2009 & All & 65 & 30 & 35 \\
\hline & & $<20$ & $45(69.2)$ & $19(63.3)$ & $26(74.3)$ \\
\hline & & 20-39 & $14(21.5)$ & $7(23.3)$ & $7(20.0)$ \\
\hline & & $40-59$ & $3(4.6)$ & $2(6.7)$ & $1(2.9)$ \\
\hline & & NA & $3(4.6)$ & $2(6.7)$ & $1(2.9)$ \\
\hline \multirow[t]{6}{*}{ Household contacts } & September-October 2009 & All & 195 & 84 & 111 \\
\hline & & $<20$ & $43(22.1)$ & $21(25.0)$ & $22(19.8)$ \\
\hline & & 20-39 & $75(38.5)$ & $34(40.5)$ & $41(36.9)$ \\
\hline & & $40-59$ & $47(24.1)$ & $21(25.0)$ & $26(23.4)$ \\
\hline & & $\geq 60$ & $19(9.7)$ & $5(6.0)$ & $14(12.6)$ \\
\hline & & NA & $11(5.6)$ & $3(3.6)$ & $8(7.2)$ \\
\hline
\end{tabular}

* 5 subjects did not report their gender, of which 1 was aged $<20$ years and other 4 had not reported their age.

$\mathrm{NA}=$ not available, $\mathrm{PCR}=$ polymerase chain reaction

The overall seropositivity among school children (631/ $2527,25 \%)$ was significantly $(\mathrm{p}<0.001)$ higher than the school staff $(19 / 177,10.7 \%)$ sampled in September (Table 2). In the schools with the reports of PCR-confirmed cases, $26.1 \%$ students were seropositive as compared to $16.3 \%$ in the schools without PCR-confirmed cases. Further, the classes with the reports of PCR-confirmed cases showed higher seropositivity than other classes (data not shown). The lowest seropositivity of $7.4 \%$ was reported in $<5$ years age group. The 15-19 years age group showed the highest seropositivity (42.2\%), followed by $10-14$ years age group $(26.7 \%)$ (Table 3). Among 631 seropositive subjects, 79 (12.5\%) reported the recent history of influenza-like illness. The highest incidence of influenza-like illness (22.6\%) was recorded in the students from 15-19 years age group. Seropositivity of $56 \%$ for seasonal H1N1 and $27.3 \%$ for seasonal H3N2 was noted in school children (data not shown).

\section{Seropositivity in other groups}

In September, seropositivity was similar among railway commuters $(13 / 225,5.8 \%)$, office-staff $(8 / 233,3.4 \%)$ and slum-dwellers (23/651, 3.5\%) (Table 2). Influenza-like illness was reported by 3 (13\%) seropositive subjects from the slums. In a general population cluster survey of 2520 subjects in October 2009, the overall seropositivity was $6 \%$. The seropositivity was similar in higher (8.3\%), middle (5.2\%) and lower (5.9\%) social strata. Males and females had similar seropositivity. The highest seropositivity of $20.3 \%$ was observed in the age group 15-19 years (data not shown). A total of 192 subjects were excluded for presenting data in Fig. 1 because age was not recorded for 17 subjects and remaining 175 subjects had lacking data on seropositivity for seasonal H1N1 and H3N2 viruses. In 2328 subjects, seropositivity among children $(73 / 790,9.2 \%)$ was significantly ( $\mathrm{p}<$ 0.001 ) higher than the adults $(59 / 1538,3.8 \%)$. Overall seropositivity of seasonal $\mathrm{H} 1 \mathrm{~N} 1$ and $\mathrm{H} 3 \mathrm{~N} 2$ in general population was $26.4 \%$ and $55.3 \%$ respectively. Whereas, among school-aged children sampled from community, seropositivity was $41.9 \%$ for seasonal $\mathrm{H} 1 \mathrm{~N} 1$ and $66.5 \%$ for seasonal H3N2. Seropositivity of H3N2 was significantly $(\mathrm{p}<0.01)$ higher than seasonal H1N1 in all age groups except $<5$ years. Seropositivity of pandemic H1N1 $(132 / 2328,5.7 \%)$ was significantly $(\mathrm{p}<0.01)$ 
Table 2 Seropositivity among different study groups at various time periods in the year 2009

\begin{tabular}{|c|c|c|c|c|c|c|}
\hline \multirow[t]{2}{*}{ Study groups } & \multirow[t]{2}{*}{ Month of 2009} & \multirow[t]{2}{*}{ No. sampled } & \multicolumn{2}{|c|}{ HI titre $\geq 1: 10$} & \multicolumn{2}{|c|}{ HI titre $\geq 1: 40$} \\
\hline & & & No. & $\%(95 \% \mathrm{Cl})$ & No. & $\%(95 \% \mathrm{Cl})$ \\
\hline \multirow[t]{3}{*}{ Hospital staff } & August & 495 & 43 & $8.7(6.2-11.2)$ & 14 & $2.8(1.4-4.3)$ \\
\hline & October & 524 & 40 & $7.6(5.4-9.9)$ & 25 & $4.8(3.0-6.5)$ \\
\hline & November & 385 & 77 & $20.0(16.0-23.9)$ & 46 & $12.0(8.7-15.1)$ \\
\hline \multirow[t]{3}{*}{ General practitioners } & August & 385 & 62 & $16.1(12.4-19.8)$ & 19 & $4.9(2.8-7.0)$ \\
\hline & November & 278 & 67 & $24.1(19.1-29.1)$ & 26 & $9.4(5.9-12.8)$ \\
\hline & December & 225 & 80 & $35.6(29.3-41.8)$ & 34 & $15.1(10.4-19.8)$ \\
\hline \multirow[t]{2}{*}{ School staff } & August & 348 & 23 & $6.6(3.9-9.2)$ & 7 & $2.0(0.5-3.5)$ \\
\hline & September & 177 & 46 & $26.0(19.5-32.5)$ & 19 & $10.7(6.2-15.3)$ \\
\hline School children & September & 2527 & 800 & $31.7(29.8-33.5)$ & 631 & $25.0(23.3-26.7)$ \\
\hline Railway commuters & September & 225 & 27 & $12.0(7.8-16.3)$ & 13 & $5.8(2.7-8.8)$ \\
\hline Office staff & September & 233 & 25 & $10.7(6.8-14.7)$ & 8 & $3.4(1.0-5.8)$ \\
\hline Slum-dwellers & September & 651 & 67 & $10.3(8.0-12.6)$ & 23 & $3.5(2.1-5.0)$ \\
\hline General population & October & 2520 & 242 & $9.6(8.4-10.8)$ & 151 & $6.0(5.1-6.9)$ \\
\hline PCR-confirmed cases & September- October & 65 & 53 & 81.5 (72.1-91.0) & 48 & $73.8(63.2-84.5)$ \\
\hline Household contacts & September- October & 195 & 70 & $35.8(29.2-42.6)$ & 50 & $25.6(19.5-31.8)$ \\
\hline
\end{tabular}

$\mathrm{Cl}=$ confidence interval, $\mathrm{HI}=$ haemagglutination-inhibition, $\mathrm{PCR}=$ polymerase chain reaction

lower than seasonal H3N2 in all age groups. Also, seropositivity of pandemic H1N1 was significantly lower than seasonal H1N1 in all age groups except in those aged $\geq 70$ years (Fig. 1 ). The highest seropositivity of $19.6 \%$ for pandemic H1N1 was observed in $15-19$ years age group followed by $7.2 \%$ in $10-14$ years, $5.5 \%$ in 20 29 years and $4.7 \%$ in $30-39$ years (Fig. 1). The lowest seropositivity of $1.3 \%$ was observed in 60-69 years age group. On direct age-standardization, age-adjusted seropositivity was similar to the age-specific seropositivity (data not shown).

\section{Household contacts of the PCR-confirmed cases}

Among 195 household contacts of 74 PCR-confirmed cases, 50 (25.6\%) were seropositive (Table 2). Among these, 7 (14\%) reported influenza-like illness within 2-7 days of the onset of illness in the index case. The agespecific seropositivity was the highest in 5-19 years age

Table 3 Seropositivity in different age groups among school children in September 2009

\begin{tabular}{|c|c|c|c|c|c|}
\hline \multirow{2}{*}{$\begin{array}{c}\text { Age group } \\
\text { (years) }\end{array}$} & \multirow{2}{*}{$\begin{array}{c}\text { No. } \\
\text { sampled }\end{array}$} & \multicolumn{2}{|c|}{$\mathrm{HI}$ titre $\geq 1: 10$} & \multicolumn{2}{|c|}{$\mathrm{HI}$ titre $\geq 1: 40$} \\
\hline & & No. & $\%(95 \% \mathrm{Cl})$ & No. & $\%(95 \% \mathrm{Cl})$ \\
\hline$<5$ & 149 & 12 & $8.1(3.7-12.4)$ & 11 & $7.4(3.2-11.6)$ \\
\hline $5-9$ & 821 & 203 & $\begin{array}{c}24.7(21.8- \\
27.7)\end{array}$ & 164 & $\begin{array}{c}20.0(17.2- \\
22.7)\end{array}$ \\
\hline $10-14$ & 1306 & 446 & $\begin{array}{c}34.2(31.6- \\
36.7)\end{array}$ & 350 & $\begin{array}{c}26.7(24.3- \\
29.2)\end{array}$ \\
\hline $15-19$ & 251 & 139 & $\begin{array}{c}55.4(49.2- \\
61.5)\end{array}$ & 106 & $\begin{array}{c}42.2(36.1- \\
48.3)\end{array}$ \\
\hline Total & 2527 & 800 & $\begin{array}{c}31.7(29.8- \\
33.5)\end{array}$ & 631 & $\begin{array}{c}25.0(23.3- \\
26.7)\end{array}$ \\
\hline
\end{tabular}

$\mathrm{Cl}=$ confidence interval, $\mathrm{HI}=$ haemagglutination-inhibition group (40\%), followed by 20 -39 years age group (30.7\%) (data not shown).

We further analyzed the proportions of subjects from different study groups whose sera were detected with the minimum detectable HI antibody titre of 1:10 (Table 2). Seroconversion in PCR-confirmed pandemic H1N1 cases was $81.5 \%$. In the hospital staff, this proportion was $8.7 \%$ in August, $7.6 \%$ in October and 20\% in November. Among general practitioners, these proportions were $16.1 \%$ in August, $24.1 \%$ in November and $35.6 \%$ in December. In school staff, positivity was $6.6 \%$ in August and 26\% in September. School children had the highest positivity of $31.7 \%$ in September. In the schools, $55.4 \%$ of those aged $15-19$ years and $34.2 \%$ of those aged 10-14 years were positive (Table 3 ). In other groups, these proportions were- $12 \%$ in railway commuters, $10.7 \%$ in office staff and $10.3 \%$ in slum-dwellers in September (Table 2). In general population, 9.6\% subjects were positive, the highest of $28.4 \%$ in the age group of 15-19 years. In household contacts of PCRconfirmed cases, positivity was $35.8 \%$. Overall, considering a titre cut off of 1:10, positivity was 1.5 - 3 times as compared to the titre cut off 1:40.

\section{Discussion}

This is the first report of population-based large-scale serological surveys undertaken during the continuing influenza A (H1N1) 2009 pandemic in India. We also report the repeat surveys among adults in the selected risk groups for new infections over 5-13 weeks period and secondary infections among household contacts of the PCR-confirmed cases. We have surveyed a large number of schoolaged children in the study. A recent report from New 


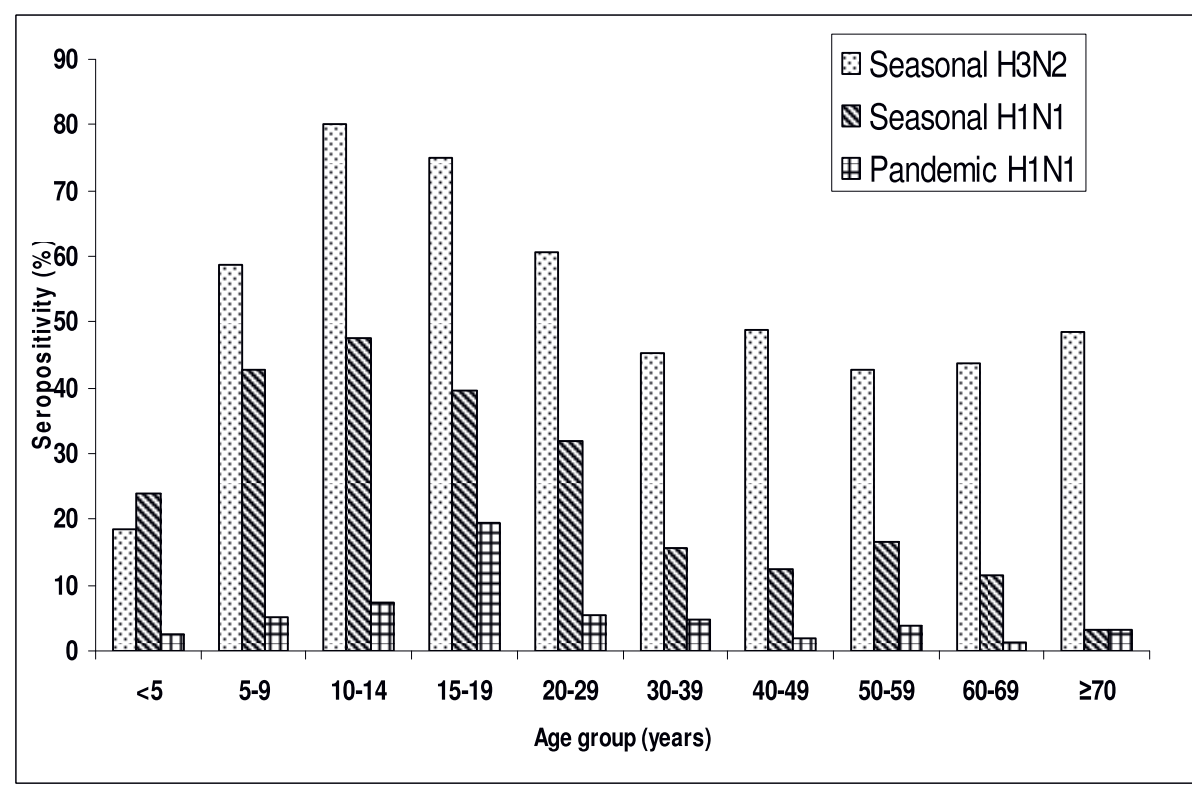

Figure 1 Age-specific seropositivity of seasonal H3N2, seasonal H1N1 and pandemic H1N1 viruses in the general population in October $2009(n=2328)$.

Zealand investigated 521 pre-pandemic sera and surveyed 1156 subjects (including 361 children) from community and 540 healthcare workers at the end of first wave [16]. Another study from Singapore investigated 727 adult community participants and 537 hospital staff [17]. A review of seroepidemiological studies clearly indicated the need of more studies using standardized methods to be able to accurately estimate global infection rate [18].

Seropositivity in the pre-pandemic period was negligible $(0.9 \%)$ in our study. Other studies reported seropositivity in pre-pandemic sera at different levels $[5-10,19]$. A recent study from Singapore observed no or minimal cross-reactivity $[17,20]$. Indian population has experienced co-circulation of seasonal and pandemic viruses with almost equal contribution during the study period [2]. Also, seasonal influenza vaccination uptake is negligible. Seropositivity in the PCR-confirmed cases was $73.8 \%$ considering a cut off of 1:40 and 81.5\% considering 1:10. Similar seroconversion of $89.1 \%$ in PCR-confirmed cases was reported using a titre cut-off of 1:32 in England [9].

The highest seropositivity was observed in the school children and the staff. Seropositivity was higher among students in the divisions with PCR-confirmed cases than in other divisions. Repeat serosurvey in school staff indicated significant increase in seropositivity after 5 weeks. The academic school calendar starts from June and continues through March. Seropositivity of 52\% among 415 school children and staff in a residential school in Panchgani, India using a cut off titre of 1:10 [21] was higher than $31.7 \%$ in our study. Similar observations on incidence of influenza disease were reported during the school outbreaks in London [22] and New York [23]. In the UK, schools were identified as the most important source of infection [24]. Higher seropositivity in schools than households and communities could be attributed to the sustained close contact favouring transmission among the susceptible age groups [16].

In August, seropositivity among general practitioners (4.9\%) was higher than the hospital staff (2.8\%). During the repeat serosurvey, seropositivity was almost three times higher among general practitioners after 13 weeks. Among hospital staff, seropositivity was two times higher after 9 weeks. The higher seropositivity among general practitioners may be attributed to the higher possibility of contact with the patients as general practitioners are the first point of contact for influenza-like illness. Lack of infection-control practices may be another important reason. A study in Taiwan [11] reported 20\% seropositivity among 295 hospital staff. Seropositivity of $29.6 \%$ in hospital staff and $25.3 \%$ in primary healthcare staff at the end of first wave in New Zealand indicated no additional risk to the healthcare workers as compared to general community (26.7\%) [16]. The lower seropositivity among hospital staff in our study may be due to the widespread use of both therapeutic and prophylactic antiviral therapy and other infection-control measures.

In our study, higher seropositivity was noted in 15-19 years age group in both schools (42.2\%) and in general population (20.3\%). Seropositivity was lower in elderly population indicating low infection rates (Fig. 1). The incidence, severity and mortality of pandemic H1N1 
disease was also lower in elderly than in other age groups in the study area [2]. The similar lower incidence of infection was reported in elderly in New Zealand [16]. This is also similar to the studies in some other countries [5-10]. It indicates that the pre-existing immunity and cross-reactivity levels vary in populations and age groups [20]. Seropositivity among elderly in China has been reported to be $9.4 \%$ in pre-pandemic and $42.5 \%$ in post-pandemic sera [25]. The likely hypotheses being forwarded include the differential exposures [26], the role of cell-mediated immunity [27] and immune epitopes or genetic differences [6].

Seropositivity of $25.6 \%$ in household contacts of the PCR-confirmed cases and influenza-like illness in $14 \%$ of those seropositive is noteworthy. The incidence of influenza-like illness among household contacts in our study was similar to the secondary attack rate of $13 \%$ detected in the USA [27]. The transmission of the pandemic H1N1 2009 virus is reported to be less-efficient in households as compared to the school settings [23]. It is also likely that the infections were mild, unnoticed or not remembered by the household members [23]. The widespread use of oseltamivir therapy in suspected cases and their household contacts, hospital or home isolation and the other prevention practices might have contributed to the lower infections in the household contacts. Postexposure oseltamivir prophylaxis has been reported to reduce the rate of infection during outbreaks [28].

In our study, symptomatic infection was around $10 \%$. Incidence of influenza-like illness among those identified with the serological infections in schools, hospital staff and general practitioners was similar to that reported in France [29], New Zealand [16,30] and the USA [31]. The $20-40 \%$ infections were reported to be symptomatic in the 1957 and 1968 pandemics [32,33]. The percentage of asymptomatically infected subjects was estimated at 2-10 times of the clinical cases during the current pandemic $[9,34]$. The asymptomatic infections seem to play an important role in transmission of the pandemic H1N1 virus as evidenced recently by RNA detection in persons with subclinical infection [35].

The possibility of underestimation of seropositivity may be due to the specificity and the threshold titre of HI assay [16]. This is evident from the data presented with a minimum detectable titre of 1:10 as compared to 1:40. The sera treated with turkey red blood cells were few and randomly distributed. We do not consider that these led to biases in the study. The pandemic H1N1 infections are widespread and mostly subclinical or mild. Asymptomatic or mild infections are reported to have low antibody titres as compared to clinically manifested patients [11]. There is under-representation of some age groups in general population. Information about underlying health conditions of 222 subjects sampled during pre-pandemic period could not be made available. Comparison of serology data with the incidence of clinical disease was not possible due to the non-availability of baseline seropositivity in representative pre-pandemic sera, non-reliability of disease incidence estimates due to changing policies of sampling and testing of throat swab specimens at different time periods, and co-circulation of seasonal and pandemic viruses in the community. We have certain limitations in estimation of incidence of infection as we could study only the adults by repeat surveys and limited number of household contacts of PCR-confirmed cases. Different levels of morbidity and mortality have been reported in different cities of India. Further serological surveys in different cities in India may help us understand infection rates and the factors responsible for such variation.

\section{Conclusions}

We conclude that the schools played an important role for transmission of pandemic influenza A (H1N1) 2009 virus infections. General practitioners were at higher risk than the hospital staff. There is a need to provide health education regarding infection-control practices to these groups. The study may also help in prioritization for vaccination.

\section{Abbreviations \\ HI: Haemagglutination-inhibition; PCR: Polymerase chain reaction; RNA: Ribonucleic acid.}

\section{Acknowledgements}

Authors are indebted to Dr MD Gupte and Dr SM Mehendale for guidance and expert advice during the design and analytical phases of the study. We gratefully acknowledge the scientists Dr VA Arankalle and Dr C Dayaraj for providing pre-pandemic archived sera. We are thankful to Dr Dilip Sarda and Dr Anil Bhandwalkar for support during field operations. We acknowledge YD Sable, PA More, Vasanthy Venkatesh, S Pagar, AM Walimbe, MR Khude, BD Walhekar, VA Sonawane, SS Kode, PB Kulkarni, R Singh, H Sooryanarayan, JPN Babu, SK Waghmare and Dr MD Gokhale for supporting the field, laboratory and data management activities. We acknowledge the health officers and staff, students and their parents, and other study participants. We are thankful to Dr AN Latey for editing the manuscript. We acknowledge the financial support from the Indian Council of Medical Research, New Delhi.

\section{Authors' contributions}

BVT planned and designed field studies, executed and supervised field activities including collection of sera specimens, data collection and management, data analysis and interpretation, and wrote and revised the manuscript drafts. SDP standardized and supervised the assays, analyzed data and contributed in revising the manuscript drafts. YKG contributed in execution and supervision of field activities, and revising the manuscript drafts. MSC had significant inputs in planning, designing and guiding the field activities. SSK performed the assays and supervised the laboratory activities. VNS contributed in executing and supervising the field activities. ACM substantially contributed to the study design, guidance during field operations, interpretation of the results, reviewing and editing the

manuscript drafts. All authors critically reviewed the drafts and approved the final manuscript

\section{Competing interests}

The authors declare that they have no competing interests. 
Received: 10 April 2010 Accepted: 25 August 2010

Published: 25 August 2010

\section{References}

1. Ministry of Health and Family Welfare, Government of India: Update of influenza $\mathrm{A}(\mathrm{H} 1 \mathrm{~N} 1)$ as on 17th May, 2009. Press release dated 17th May, 2009 [http://mohfw.nic.in/Status_as_on_16.5.2009_at_4.30_p.m.doc], [Dated 15 Jun 2010].

2. Mishra AC, Chadha MS, Choudhary ML, Potdar VA: Pandemic influenza (H1N1) 2009 is associated with severe disease in India. PLoS One 2010, 5(5):e10540

3. World Health Organization: Human infection with new influenza A (H1N1) virus: clinical observations from Mexico and other affected countries, May 2009. Wkly Epidemiol Rec 2009, 84:185-189.

4. Lipsitch M, Riley S, Ferguson NM: Managing and reducing uncertainty in an emerging influenza pandemic. N Engl J Med 2009, 361:112-115.

5. Hancock K, Veguilla V, Lu X, Zhong W, Butler EN, Sun H, Liu F, Dong L, DeVos JR, Gargiullo PM, Brammer TL, Cox NJ, Tumpey TM, Katz JM: Crossreactive antibody responses to the 2009 pandemic H1N1 influenza virus. N Engl J Med 2009, 361:1945-1952.

6. Xing Z, Cardona CJ: Preexisting immunity to pandemic (H1N1). Emerg Infect Dis 2009, 15:1847-1849.

7. Chen H, Wang Y, Liu W, Zhang J, Dong B, Fan X, de Jong MD, Farrar J, Riley S, Smith GJ, Guan Y: Serologic survey of pandemic (H1N1) 2009 virus, Guangxi Province, China. Emerg Infect Dis 2009, 15:1849-1850.

8. Ikonen N, Strengell M, Kinnunen L, Osterlund P, Pirhonen J, Broman M, Davidkin I, Ziegler T, Julkunen I: High frequency of cross-reacting antibodies against 2009 pandemic influenza $A(\mathrm{H} 1 \mathrm{~N} 1)$ virus among the elderly in Finland. Euro sunveill 2010, 15:pii:19478.

9. Miller E, Hoschler K, Hardelid P, Stanford E, Andrews N, Zambon M: Incidence of 2009 pandemic influenza A H1N1 infection in England: a cross-sectional serological study. Lancet 2010, 375:1100-1108.

10. Ross T, Zimmer S, Burke D, Crevar C, Carter D, Stark J, Giles B, Zimmerman R, Ostroff S, Lee B: Seroprevalence following the second wave of pandemic 2009 H1N1 influenza. PLoS Curr Influenza 2010, RRN1148.

11. Chan YJ, Lee CL, Hwang SJ, Fung CP, Wang FD, Yen DH, Tsai CH, Chen YM, Lee SD: Seroprevalence of antibodies to pandemic (H1N1) 2009 influenza virus among hospital staff in a medical center in Taiwan. J Chin Med Assoc 2010, 73:62-66.

12. Allwinn R, Geiler J, Berger A, Cinatl J, Doerr HW: Determination of serum antibodies against swine-origin influenza $A$ virus $\mathrm{H} 1 \mathrm{~N} 1 / 2009$ by immunofluorescence, haemagglutination inhibition, and by neutralization tests: how is the prevalence rate of protecting antibodies in humans? Med Microbiol Immunol 2010, 199(2):117-121.

13. World Health Organization (WHO). Global influenza programme: WHO manual on animal influenza diagnosis and surveillance, WHO/CDS/CSR/ NCS. [http://www.who.int/vaccine_research/diseases/influenza/ WHO_manual_on_animal-diagnosis_and_surveillance_2002_5.pdf], [Dated 15 Jun 2010].

14. Rowe T, Abernathy RA, Hu-Primmer J, Thompson WW, Lu X, Lim W, Fukuda K, Cox NJ, Katz JM: Detection of antibody to Avian Influenza A (H5N1) virus in human serum by using a combination of serologic assays. J Clin Microbiol 1999, 37:937-943.

15. World Health Organization (WHO): Age standardization of rates: A new WHO standard. GPE Discussion paper series No. 31 [http://who.int/ healthinfo/paper31.pdf], [Dated 15 Jun 2010].

16. Ministry of Health, New Zealand: Seroprevalence of the 2009 influenza A (H1N1) pandemic in New Zealand. [http://www.nzdoctor.co.nz/media/ 224143/seroprevalence-flu-2009.pdf], [Dated 15 Jun 2010].

17. Chen MIC, Lee VJM, Lim W-Y, Barr IG, Lin RTP, Koh GCH, Yap J, Cui L, Cook AR, Laurie K, Tan LWL, Tan BH, Loh J, Shaw R, Durrent C, Chow VTK, Kelso A, Chia KS, Leo YS: 2009 influenza $A(\mathrm{H} 1 \mathrm{~N} 1)$ seroconversion rates and risk factors among distinct adult cohorts in Singapore. JAMA 2010, 303(14):1383-1391.

18. World Health Organization: Seroepidemiological studies of pandemic influenza A (H1N1) 2009 virus. Wkly Epidemiol Rec 2010, 85:229-236.

19. Epstein SL: Prior H1N1 influenza infection and susceptibility of Cleveland family study participants during the H2N2 pandemic of 1957: an experiment of nature. $J$ Infect Dis 2006, 193:49-53.
20. Tang JW, Tambyah PA, Wilder-Smith A, Puong K-Y, Shaw R, Barr IG, Chan KP: Cross-reactive antibodies to pandemic (H1N1) 2009 virus, Singapore. Emerg Infect Dis 2010, 16(5):874-876.

21. Gurav YK, Pawar SD, Chadha MS, Potdar VA, Deshpande AS, Koratkar SS, Hosmani AH, Mishra AC: Pandemic influenza A (H1N1) 2009 outbreak in a residential school in Panchgani, Maharashtra, India. Indian J Med Res 2010, 132:67-71.

22. Calatayud L, Kurkela S, Neave PE, Brock A, Perkins S, Zuckerman M, Sudhanva M, Bermingham A, Ellis J, Pebody R, Catchpole M, Heathcock R, Maguire H: Pandemic (H1N1) 2009 virus outbreak in a school in London, April-May 2009: an observational study. Epidemiol Infect 2010, 138:183-191.

23. Lessler J, Reich NG, Cummings DA, New York City Department of Health and Mental Hygiene Swine Influenza Investigation Team, Nair HP, Jordan HT, Thompson N: Outbreak of 2009 pandemic influenza A (H1N1) at a New York City school. N Engl J Med 2009, 361:2628-2636.

24. Ghani AC, Baguelin M, Griffin J, Flasche S, Pebody R, van Hoek AJ, Cauchemez S, Hall IM, Donnelly C, Robertson C, White MT, Barrass I, Fraser C, Bermingham A, Truscott J, Ellis J, Jenkins H, Kafatos G, Garske T, Harris R, McMenamin J, Hawkins C, Phin N, Charlett A, Zambon M, Edmonds WJ, Catchpole M, Leach S, White P, Ferguson NM, Cooper B: The early transmission dynamics of H1N1 pdm influenza in the United Kingdom. PLoS Curr Influenza 2009, RRN1130.

25. Jiang T, Li X, Liu W, Yu M, Liu J, Yu X, Qin E, Cao W, Leng Q, Qin C: Serum antibody response to the novel influenza $A(\mathrm{H} 1 \mathrm{~N} 1)$ virus in the elderly. Clin Infect Dis 2010, 50:285-286.

26. Chowell G, Bertozzi SM, Colchero MA, Lopez-Gatell H, Alpuche-Aranda C, Hernandez M, Miller MA: Severe respiratory disease concurrent with the circulation of H1N1 influenza. N Engl J Med 2009, 361:674-679.

27. Cauchemez S, Donnelly CA, Reed C, Ghani AC, Fraser C, Kent CK, Finelli L, Ferguson NM: Household transmission of 2009 pandemic influenza A (H1N1) virus in the United States. N Engl J Med 2009, 361:2619-2627.

28. Lee VJ, Yap J, Tay JK, Barr I, Gao Q, Ho HJ, Tan BH, Kelly PM, Tambyah PA, Kelso A, Chen Ml: Seroconversion and asymptomatic infections during oseltamivir prophylaxis against influenza A H1N1 2009. BMC Infect Dis 2010.

29. Flahault A, de Lamballerie X, Hanslik T, Salez N: Symptomatic infections less frequent with $\mathrm{H} 1 \mathrm{~N} 1 \mathrm{pdm}$ than with seasonal strains. PLoS Curr Influenza 2009, RRN1140.

30. Baker MG, Wilson N, Huang QS, Paine S, Lopez L, Bandaranayake D, Tobias M, Mason K, Mackereth GF, Jacobs M, Thornley C, Roberts S, McArthur C: Pandemic influenza A (H1N1)v in New Zealand: the experience from April to August 2009. Euro Surveill 2009, 14:pii:19319.

31. Presanis AM, De Angelis D, New York City Swine Flu Investigation Team, Hagy A, Reed C, Riley S, Cooper BS, Finelli L, Biedrzycki P, Lipsitch M: The severity of pandemic H1N1 influenza in the United states, from April to July 2009: a Bayesian analysis. PLoS Med 2009, 6:e1000207.

32. Clarke SK, Heath RB, Sutton RN, Stuart-Harris CH: Serological studies with Asian strain of influenza A. Lancet 1958, 1:814-818.

33. Viboud C, Grais RF, Lafont BA, Miller MA, Simonsen L, Multinational Influenza Seasonal Mortality Study Group: Multinational impact of the 1968 Hong Kong influenza pandemic: evidence for a smoldering pandemic. J Infect Dis 2005, 192:233-248.

34. Fraser C, Donnelly CA, Cauchemez S, Hanage WP, Van Kerkhove MD, Hollingsworth TD, Griffin J, Baggaley RF, Jenkins HE, Lyons EJ, Jombart T, Hinsley WR, Grassly NC, Balloux F, Ghani AC, Ferguson NM, Rambaut A, Pybus OG, Lopez-Gatell H, Alpuche-Aranda CM, Chapela IB, Zavala EP, Guevara DM, Checchi F, Garcia E, Hugonnet S, Roth C, WHO Rapid Pandemic Assessment Collaboration: Pandemic potential of a strain of influenza A (H1N1): early findings. Science 2009, 324:1557-1561.

35. Yang J, Yang F, Huang F, Wang J, Jin Q: Subclinical infection with the novel influenza A (H1N1) virus. Clin Infect Dis 2009, 49:1622-1623.

\section{Pre-publication history}

The pre-publication history for this paper can be accessed here: http://www.biomedcentral.com/1471-2334/10/255/prepub

doi:10.1186/1471-2334-10-255

Cite this article as: Tandale et al: Seroepidemiology of pandemic influenza A (H1N1) 2009 virus infections in Pune, India. BMC Infectious Diseases 2010 10:255. 